\title{
Ir-Ni based mono and bimetallic nanocrystals: synthesis, characterization and effect of cationic, anionic, and non-ionic stabilizers
}

\author{
Anjali Goel $^{\mathrm{a}}$, Shikha ${ }^{\mathrm{a}^{*}}$, Shivani ${ }^{\mathrm{a}}$ and Sudha Tomar ${ }^{\mathrm{a}}$
}

${ }^{a}$ Department of Chemistry, KGC, Gurukul Kangri University, Haridwar 249407, India

\begin{tabular}{l}
\hline C H R O N I C L E \\
\hline Article history: \\
Received October 12, 2020 \\
Received in revised form \\
November 30, 2020 \\
Accepted January 15, 2021 \\
Available online \\
January 15, 2021 \\
\hline Keywords: \\
Iridium \\
Nickel \\
Ethylene Glycol \\
Bimetallic Nanoparticles \\
\end{tabular}

\begin{abstract}
A B S T R A C T
Nickel based bimetallic nanocrystals, iridium-nickel play an imperative role in catalysis, electrocatalysis, and magnetic applications. In the present work Ir-Ni bimetallic nanoalloys were synthesized by modified polyol reduction method with different cationic, anionic, and non-ionic surface active agents like CTAB, SDS, TSC, and PVP. The non-ionic surface active agent PVP produced a better effect on nanoparticle size than cationic and anionic surfactants. The synthesized bimetallic nanocrystals were characterized by UV-Vis, XRD, FTIR, FESEM, and HRTEM techniques. XRD and FTIR verify the nature of synthesized bimetallic nanocrystals and the interaction between stabilizers and nanoparticles. HRTEM studies reveal that the PVP stabilized Ir-Ni (3:1) and Ir-Ni (1:1) bimetallic nanocrystals are small in size and less dispersed. Particle size range of these nanoparticles is from $(1.77-2.36) \mathrm{nm}$. FESEM images show that nanoparticles are in quasi spherical shape. EDX analysis indicates that the resultant particles are core shell structure with Ni core and Ir shell.
\end{abstract}

\section{Introduction}

Nanoparticles are the nanometer-sized sturdy particles, negotiated at atomic or molecular scale, to perform either novel or superior physical properties that are not feasible by conventional bulk solids. In the last several years nanotechnology, has evolved as a cutting edge technology interdisciplinary with physical science, biology, chemical science, medicine and material science. ${ }^{1}$ Nanocrystals have been enterprised in populous consumer merchandise such as in sunblocker, superficial, paint, implements, computer devices etc. ${ }^{2}$ Transition metal nanocrystals are known to be constructive catalysts for chemical alterations due to their large surface area. ${ }^{3}$ Iridium is the part of platinum family and used as energizer due to its mercurial oxidation states. It is known as the most erosion resistant component even at temperatures as high as $2000^{\circ} \mathrm{C}$. Erosion and heat resistant peculiarities of iridium make it much more lucrative element for alloying aspiration. ${ }^{4}$ Its composites were first inspected for their antineoplastic activity shortly after the disclosure of cis platin. ${ }^{5}$ It is eminent for boosting olefin, aldehyde, and ketone hydrogenation with more reactions viable when used in bimetallism. ${ }^{6} \mathrm{Nickel}$ is a imperative passage metal. ${ }^{7}$ Goodman et al. found that the catalytic action of Ni activator was marginally inferior to that of ruthenium, iridium, and rhodium based promoters. ${ }^{8}$ It is the preferred nanocatalyst for numerous reactions owing to its life, immense activity, and relatively economical price. ${ }^{9}$ Specially,

* Corresponding author. Tel.: +7465829823

E-mail address: shikhatomar348@gmail.com (Shikha)

(C) 2021 Growing Science Ltd. All rights reserved. doi: $10.5267 /$ j.ccl.2021.1.005 
the Ir-Ni system was depicted for hydrogen formation by electrocatalytic water splitting or by catalytic hydrazine disintegration as well as for catalytic hydrogen oxidation reactions and for ring opening reactions. ${ }^{10}$

Bimetallic nanocrystals (BMNPs) are of massive significance by virtue of the alteration of properties examined, correlated with monometallics, not only due to size effects, but also as an outcome of the merger of various metals. ${ }^{11}$ Literally, through bimetallization the catalytic attributes of the resulting nanocrystals can be upgraded to great extent which cannot be attained by the use of monometaliic energizers. In bimetallic promoters, the photoelectric impact plays an important role which defines the charge alteration. ${ }^{12}$ Numerous preparedness techniques of the nanocrystals such as electrolysis, polyol reduction, citrate reduction, $\Upsilon$ ray irradiation, organometallic methods, and sol-gel techniques have been nominated. ${ }^{13}$ In all these techniques, polyol reduction is prevalent and auspicious technique for the fusion of Ir-Ni BMNPs. ${ }^{14}$

Bimetallic nanocomposites have a thermodynamic propensity to aggregate. ${ }^{15}$ Agglomeration has lethal effects such as deferment in ignition and partial combustion of the particles as vigorous, substantial. ${ }^{16}$ Therefore surface active agents are used for the kinetic control of nanocrystals shape, morphology, and size. ${ }^{17}$.

Surface active agents or stabilizers automatically diminish the particle size without altering the structure and reducing ability depending on the type of surfactants. ${ }^{18}$ Surface active agents can be determined according to the charge exist in the hydrophilic part of the fragment i.e. cationic, anionic, amphoteric, and non-ionic surfactants. ${ }^{19}$ Cetyltrimethylammonium bromide is a cationic surfactant, ${ }^{20}$ which works as to regulate the phase structure and morphology of the product. ${ }^{21}$ Sodium dodecyl sulphate is an anionic surface active agent and used as homecleansers, in shampoos and in dentifrices. ${ }^{22}$ Tri sodium citrate is also an anionic surface active agent and it concedes easy growing and lowering the interfacial tension of the solvent. ${ }^{23}$ Polyvinylpyrrolidone is a non-ionic surface active agent. ${ }^{24}$ It is harmless and solvable in many polar solvents. PVP stabilized native metal nanocrystals have widely been used as stimulant for numerous reactions. ${ }^{25}$

Ethylene glycol is the uncomplicated diol. It is thoroughly mixable with numerous polar solvents and only marginally miscible in non-polar solvents. ${ }^{26}$ It performs as both solvent and reductive agent. ${ }^{27}$ In the present work, we have synthesized Ir-Ni bimetallic nanocrystals with (3:1), (1:3), and (1:1) ratios by polyol reduction method, using cationic (CTAB), anionic (SDS, TSC) and non-ionic (PVP) capping agents. These particles were explored using UV-Visible, XRD, FESEM, HRTEM, FTIR methods of analysis.

\section{Results and Discussion}

\subsection{UV-Vis spectrophotometry}

The UV-Vis spectra were measured after the reduction of metal ions to form nanocrystals using ethylene glycol as a reference solution. The absorption spectra of Ir, Ni monometallic (MNPs) and Ir$\mathrm{Ni}$ bimetallic nanocrystals in different molar ratios $(1: 1,3: 1$, and 1:3) using different surface active agents PVP, CTAB, SDS, and TSC are shown in Fig. 1(A), 1(B), 1(C), and 1(D). Ascan be seen in Fig. 1(A) that the absorption peaks of precursor salt of (a) $\operatorname{Ir}(\mathrm{III}) / \mathrm{PVP},(\mathbf{b}) \operatorname{Ir}(\mathrm{III}) / \mathrm{SDS}$, (c) $\operatorname{Ir}(\mathrm{III}) / \mathrm{CTAB}$, and (d) $\operatorname{Ir}(\mathrm{III}) /$ TSC stabilized are $234 \mathrm{~nm}, 239 \mathrm{~nm}, 330 \mathrm{~nm}$, and $236.8 \mathrm{~nm}$ respectively which on reduction by alcohol shifted to $358 \mathrm{~nm}, 362.2 \mathrm{~nm}, 391 \mathrm{~nm}$, and $356.8 \mathrm{~nm}$ respectively. The shifted peaks are stable and indicate the formation of Ir/surfactant assisted nanocrystals. ${ }^{28}$ The characteristic peaks of initial mixture of Ni(II)/surfactants CTAB, SDS, TSC, and PVP are $395.2 \mathrm{~nm}, 390.4 \mathrm{~nm}, 383.2 \mathrm{~nm}$, and 330nm respectively. These peaks are disappeared in Fig. 1(B) and new stable peaks are observed in (a, b, c, and $\mathbf{d}$ ) at $361.6 \mathrm{~nm}, 366.4 \mathrm{~nm}, 359.2 \mathrm{~nm}$, and at $412 \mathrm{nmfor} \mathrm{Ni} /$ surfactant i.e. CTAB, SDS, TSC, and PVP

supported nanocrystals respectively. ${ }^{9}$ The color of the solution changes from greenish yellow to pale 
brown. Color change of the solution also indicates the reduction of metal ions and formation of new species.

Two characteristic peaks are expected for a physical combination of Ir and Ni monometallic nanoparticles (MNPs) but presence of only one new absorption peak in Fig. 1(C)and 1(D) represents clearly the formation of Ir-Ni BMNPs. The characteristic peaks of Ir-Ni (1:1) BMNPs are shown in Fig. 1(C). The absorption band of Ir-Ni/surfactant- SDS, CTAB, PVP, and TSC stabilized BMNPs in $(\mathbf{a}, \mathbf{b}, \mathbf{c}$, and $\mathbf{d})$ are observed at $390.4 \mathrm{~nm}, 560.8 \mathrm{~nm}, 358.4 \mathrm{~nm}$, and $368.8 \mathrm{~nm}$ respectively. The absorption spectra of Ir-Ni (3:1,\&1:3) BMNPs are shown in Fig. 1(D). In the spectra (a, b, c, d, and e) the formation of new absorption peaks at $376 \mathrm{~nm}, 361.6 \mathrm{~nm}, 558.4 \mathrm{~nm}, 395 \mathrm{~nm}$ and $371 \mathrm{~nm}$ for Ir-Ni (3:1) and $\mathrm{Ir}-\mathrm{Ni}$ (1:3), respectively, represent the formation of BMNPs. The color of the solution turned from pale yellow to blackish brown. Maximum absorption band shifting from monometallic Ir and Ni characteristic peaks depends upon their molar ratios i.e. for Ir-Ni (3:1) shows more shifting than Ir-Ni $(1: 3)$ BMNPs.
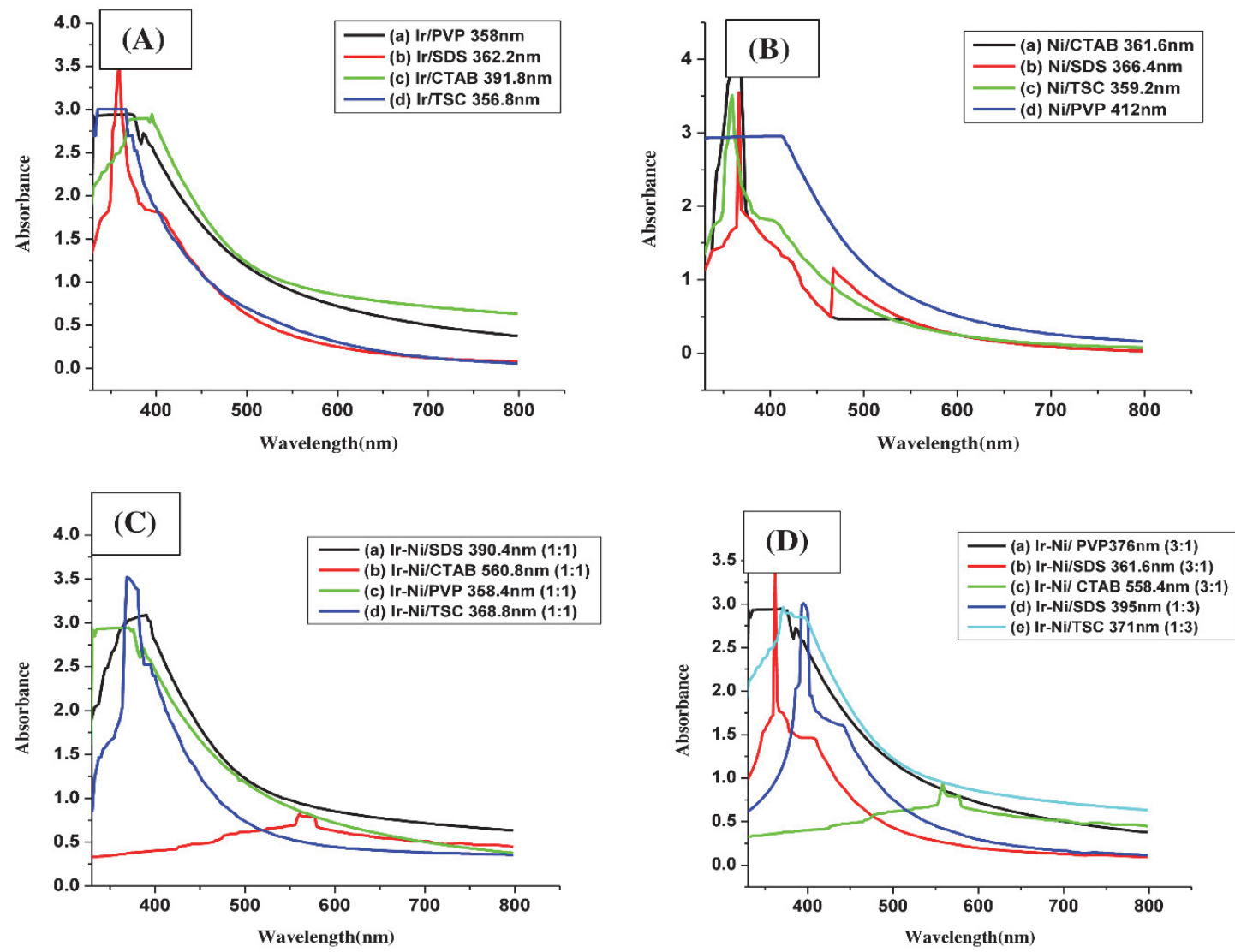

Fig. 1. UV-Vis spectra of (A) Ir MNPs formation (B) Ni MNPs formation (C)Ir-Ni (1:1) BMNPs (D) Ir-Ni (3:1, and 1:3) BMNPs by using different surfactants CTAB, PVP, SDS, and TSC.

\subsection{FT-IR (Fourier transform infrared) spectroscopy}

FT-IR characterization technique is used to identify the functional groups or molecules present in solvent and surfactant to examine their probable involvement in the synthesis of Ir-Ni/BMNPs. ${ }^{29}$ Fig. 2 shows the FTIR spectrum of (A) Ir-Ni (3:1)/PVP and (B) Ir-Ni (1:1)/PVP-BMNPs using ethylene glycol as solvent. Major peaks from FTIR spectra are selected. It was observed that pure PVP shows a strong band at $1687 \mathrm{~cm}^{-1}$ which is due to the presence of amide $>\mathrm{C}=\mathrm{O}$ group. ${ }^{30,31}$ On comparing the spectra of (A) Ir-Ni (3:1) and (B) Ir-Ni (1:1) BMNPs shifting of frequencies from 3432 to $3430 \mathrm{~cm}^{-}$ 
${ }^{1}$ are observed which suggesting the N-H stretching vibration of primary and secondary amines and amides respectively. Furthermore, a shift from 1644 to $1641 \mathrm{~cm}^{-1}$ and 1104 to $1095 \mathrm{~cm}^{-1}$ may assigned to the $\mathrm{C}=\mathrm{O}$ stretching and $\mathrm{C}-\mathrm{O}$ stretching of secondary alcohol respectively. ${ }^{32}$ From this study it is clear that the functional group like $\mathrm{N}-\mathrm{H}, \mathrm{C}=\mathrm{O}$, and $\mathrm{C}-\mathrm{O}$ are present in PVP and ethylene glycol which could possibly may stabilize and reduce the synthesized Ir-Ni BMNPs in the mixture.

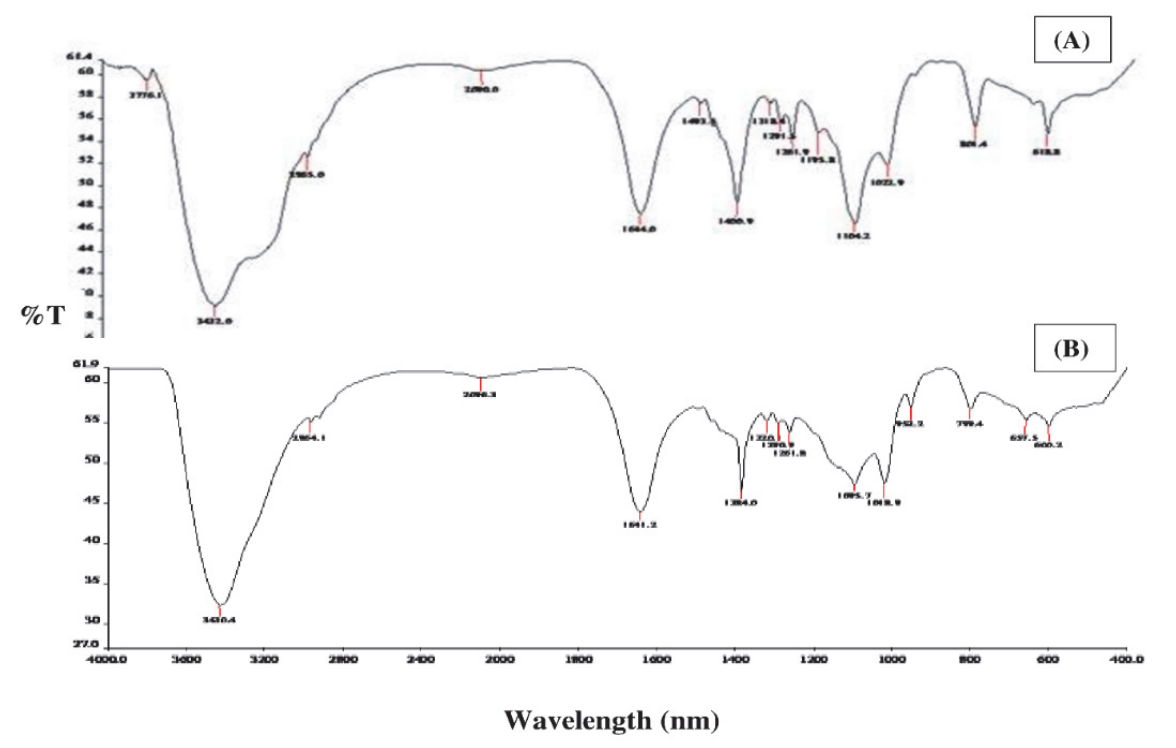

Fig. 2. FT-IR spectra of (A) Ir-Ni (3:1)/PVP and (B) Ir-Ni (1:1)/PVP-BMNPs.

\subsection{XRD (X-ray diffraction) analysis}

Crystallinity and different phases of nanocrystals were identified by X-ray diffraction analysis. ${ }^{33}$. The average particle size was calculated using Debye Scherrer equation-

$$
\mathrm{D}_{\mathrm{C}}=\frac{\mathrm{K} \Lambda}{\beta \operatorname{Cos} \theta} \text {, }
$$

where $D_{C}$ is the average crystallite size, $\beta$ is the full width of the observed diffraction peak at its half maximum intensity (FWHM), $\mathrm{K}$ is the shape factor which takes a value of about 0.9 and $K$ is the radiation wavelength which takes a value $0.154 \mathrm{~nm}$ and $\theta$ is the Bragg angle. ${ }^{34}$ The XRD spectrum of Ir, Ni monometallic nanocrystals and Ir-Ni BMNPs are shown in Fig. 3. Fig. 3(A) shows XRD spectrum of Ir MNPs using different surfactants PVP, CTAB, SDS, and TSC. XRD spectrum of Ir MNPs between $2 \theta$ of $18^{\circ}-60^{\circ}$ is shown in Fig. 3(A).

The XRD spectra of (a) Ir/PVP stabilized nano shows three peaks at $2 \theta$ about $20^{\circ}, 28^{\circ}$, and $40^{\circ}$. The peaks at $28^{\circ}$ and $40^{\circ}$ in image (a) are shifted to $26^{\circ}$ and at $40^{\circ}$ in image (b) Ir/CTAB stabilized nano. In image (c) Ir /SDS stabilized nano shows peak at $2 \theta$ about $28^{\circ}$. TSC stabilized Ir-nano in image (d) shows three diffraction peaks at $2 \theta$ about $28^{\circ}, 33^{\circ}$, and $41^{\circ}$ respectively. Broad peaks at about $28^{\circ}, 33^{\circ}$, and $40^{\circ}$ show reflection planes (110), (101), and (200) respectively which are characteristics of isolated $\mathrm{IrO}_{2}$ nanocrystals. ${ }^{35}$ The diffraction broad peaks also show the amorphous nature of the sample. ${ }^{36} \mathrm{XRD}$ spectra of Ni MNPs using different surface active agents are shown in Fig. 3(B). Two diffraction peaks of Ni/surfactant MNPs with PVP and CTAB [in image (a), and (b)] occur at $2 \theta$ values of $37.2^{\circ}$ and $43.3^{\circ}$ corresponding to (111) and (200) planes respectively. This clearly indicates that the resultant nanocrystals are in $\mathrm{NiO}$ form and represent FCC structure. Shifting of these diffraction peaks occurred at $2 \theta$ about $44.2^{\circ}$ and $51.7^{\circ}$ in Ni/surfactants (SDS, \&TSC) stabilized MNPs [in image (c), and (d)] corresponding to (111) and (200) planes respectively. XRD spectra of Ir-Ni (1:1) BMNPs using different surfactants are shown in Fig. 3(C). Ir-Ni/ surfactants (PVP, \& CTAB) stabilized BMNPs [ in 
image (a), and (b)] show two diffraction peaks at $2 \theta$ about $29.5^{\circ}$ and $41.5^{\circ}$ respectively and Ir$\mathrm{Ni} /$ surfactants (SDS, \& TSC) stabilized BMNPs show diffraction peaks at $2 \theta$ about $29.2^{\circ}$, and $43.2^{\circ}$ in image (c) and at $33.5^{\circ}$, and $46.6^{\circ}$ in image (d). On comparing with the peak of Ir MNPs the diffraction peaks of Ir-Ni BMNPs shift slightly to higher $2 \theta$ values thus verifying that the Ni has entered into the Ir lattice forming Ir-Ni alloy form. ${ }^{37}$ XRD spectrum of Ir-Ni (3:1) BMNPs using different surfactants i.e. PVP, CTAB, SDS, and TSC is shown in Fig. 3(D). The diffraction peak of Ir-Ni (3:1) bimetals in image (a), (b), (c), and (d) were observed at $2 \theta$ about $28^{\circ}$ and $40^{\circ}$ which is towards Ir monometals due to high concentration of Ir. ${ }^{32}$ The diffraction peaks for synthesized Ir-Ni nanocrystals lie between the characteristic peaks of Ir and Ni monometals thus verifying the viable formation of metal alloy or core shell structure. ${ }^{38}$ Synthesis condition and the size of particles calculated by Scherrer equation are given in Tables 1-4. Ir-Ni/ PVP stabilized BMNPs are small in size $(<10 \mathrm{~nm})$ in comparison of CTAB, SDS, and TSC stabilized nanoparticles. As we know that nanoparticles are of great importance due to their small size. Thus, only PVP stabilized particles are considered for HRTEM and FESEM analysis.

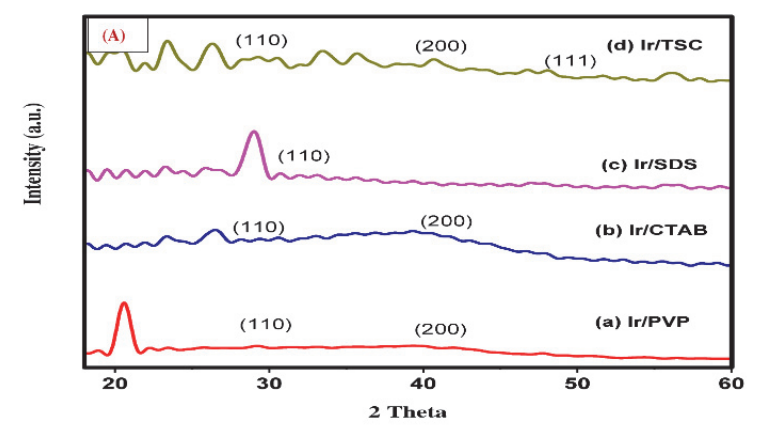

Fig. 3(A). XRD pattern of Ir MNPs using different surfactants

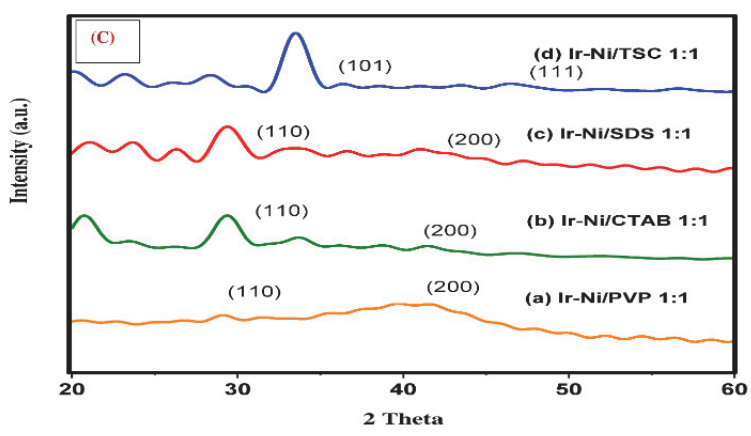

Fig. 3(C). XRD pattern of Ir-Ni (1:1) BMNPs using different surfactants

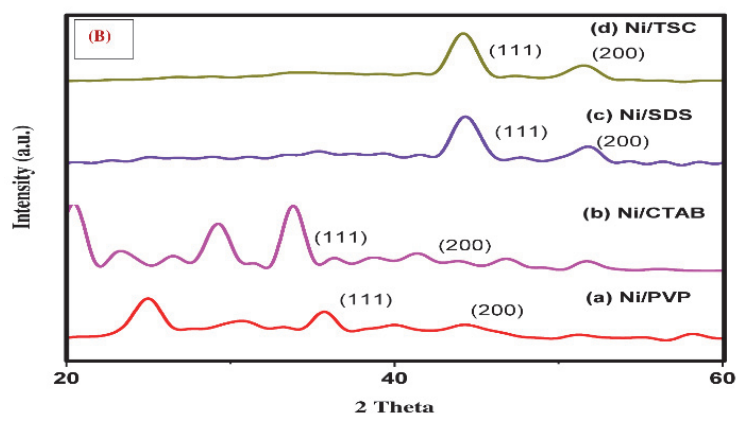

Fig. 3(B). XRD pattern of Ni MNPs using different surfactants

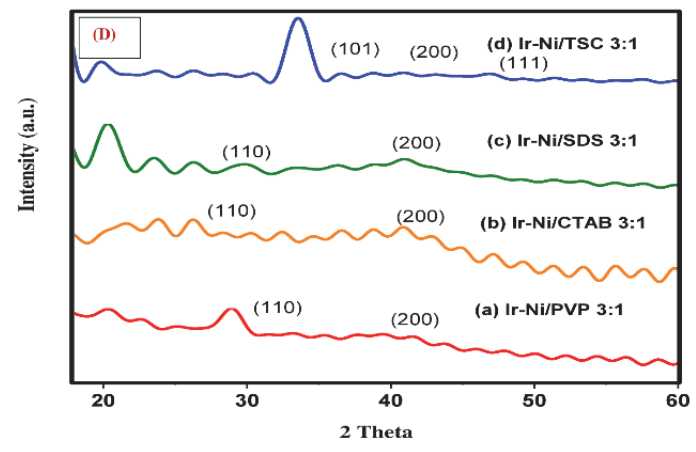

Fig. 3(D). XRD pattern of Ir-Ni (3:1) BMNPs using different surfactants

Table. 1. Synthesis conditions and particle size of Ir-Ni BMNPs with PVP

\begin{tabular}{rlcccc}
\hline \multicolumn{1}{l}{$\begin{array}{l}\text { S. } \\
\text { No. }\end{array}$} & Precursor & $\begin{array}{c}\text { Ratio of } \\
\text { precursors (\%) }\end{array}$ & Solvent & Surfactant & $\begin{array}{c}\text { Approx. particle size in } \\
\text { (nm) by XRD }\end{array}$ \\
\hline $\mathbf{1}$ & $\mathrm{IrCl}_{3} .3 \mathrm{H}_{2} \mathrm{O}$ and $\mathrm{NiCl}_{2} .6 \mathrm{H}_{2} \mathrm{O}$ & $100: 0.0$ & Ethylene glycol & PVP & 13.6 \\
$\mathbf{2}$ & $\mathrm{IrCl}_{3} .3 \mathrm{H}_{2} \mathrm{O}$ and $\mathrm{NiCl}_{2} .6 \mathrm{H}_{2} \mathrm{O}$ & $75: 25$ & Ethylene glycol & PVP & 4.8 \\
$\mathbf{3}$ & $\mathrm{IrCl}_{3} .3 \mathrm{H}_{2} \mathrm{O}$ and $\mathrm{NiCl}_{2} .6 \mathrm{H}_{2} \mathrm{O}$ & $50: 50$ & Ethylene glycol & PVP & 0.8 \\
$\mathbf{4}$ & $\mathrm{NiCl}_{2} .6 \mathrm{H}_{2} \mathrm{O}$ and $\mathrm{IrCl}_{3} .3 \mathrm{H}_{2} \mathrm{O}$ & $100: 0.0$ & Ethylene glycol & PVP & 26.5 \\
\hline
\end{tabular}


Table. 2. Synthesis conditions and particle size of Ir-Ni BMNPs with CTAB

\begin{tabular}{clclcc}
\hline S. No. & Precursor & $\begin{array}{c}\text { Ratio of } \\
\text { precursors } \\
(\mathbf{\%})\end{array}$ & Solvent & Surfactant & $\begin{array}{c}\text { Approx. particle size } \\
\text { in (nm) by XRD }\end{array}$ \\
\hline $\mathbf{1}$ & $\mathrm{IrCl}_{3} 3 \mathrm{H}_{2} \mathrm{O}$ and $\mathrm{NiCl}_{2} 6 \mathrm{H}_{2} \mathrm{O}$ & $100: 0.0$ & Ethylene glycol & CTAB & 54.3 \\
$\mathbf{2}$ & $\mathrm{IrCl}_{3} 3 \mathrm{H}_{2} \mathrm{O}$ and $\mathrm{NiCl}_{2} 6 \mathrm{H}_{2} \mathrm{O}$ & $75: 25$ & Ethylene glycol & CTAB & 33.5 \\
$\mathbf{3}$ & $\mathrm{IrCl}_{3} 3 \mathrm{H}_{2} \mathrm{O}$ and $\mathrm{NiCl}_{2} 6 \mathrm{H}_{2} \mathrm{O}$ & $50: 50$ & Ethylene glycol & CTAB & 10.3 \\
$\mathbf{4}$ & $\mathrm{IrCl}_{3} 3 \mathrm{H}_{2} \mathrm{O}$ and $\mathrm{NiCl}_{2} 6 \mathrm{H}_{2} \mathrm{O}$ & $25: 75$ & Ethylene glycol & CTAB & 10.1 \\
$\mathbf{5}$ & $\mathrm{NiCl}_{2} 6 \mathrm{H}_{2} \mathrm{O}$ and $\mathrm{IrCl}_{3} 3 \mathrm{H}_{2} \mathrm{O}$ & $100: 0.0$ & Ethylene glycol & CTAB & 59 \\
\hline
\end{tabular}

Table. 3. Synthesis conditions and particle size of Ir-Ni BMNPs with SDS

\begin{tabular}{clcccc}
\hline S. No. & Precursor & $\begin{array}{c}\text { Ratio } \\
\text { of precursors (\%) }\end{array}$ & Solvent & Surfactant & $\begin{array}{c}\text { Approx. particle } \\
\text { size in (nm) by } \\
\text { XRD }\end{array}$ \\
\hline $\mathbf{1}$ & $\mathrm{IrCl}_{3} 3 \mathrm{H}_{2} \mathrm{O}$ and $\mathrm{NiCl}_{2} .6 \mathrm{H}_{2} \mathrm{O}$ & $100: 0.0$ & Ethylene glycol & SDS & 294.6 \\
$\mathbf{2}$ & $\mathrm{IrCl}_{3} 3 \mathrm{H}_{2} \mathrm{O}$ and $\mathrm{NiCl}_{2} .6 \mathrm{H}_{2} \mathrm{O}$ & $75: 25$ & Ethylene glycol & SDS & 68.3 \\
$\mathbf{3}$ & $\mathrm{IrCl}_{3} 3 \mathrm{H}_{2} \mathrm{O}$ and $\mathrm{NiCl}_{2} 6 \mathrm{H}_{2} \mathrm{O}$ & $50: 50$ & Ethylene glycol & SDS & 246.2 \\
$\mathbf{4}$ & $\mathrm{IrCl}_{3} .3 \mathrm{H}_{2} \mathrm{O}$ and $\mathrm{NiCl}_{2} 6 \mathrm{H}_{2} \mathrm{O}$ & $25: 75$ & Ethylene glycol & SDS & 36.6 \\
$\mathbf{5}$ & $\mathrm{NiCl}_{2} 6 \mathrm{H}_{2} \mathrm{O}$ and $\mathrm{IrCl}_{3} .3 \mathrm{H}_{2} \mathrm{O}$ & $100: 0.0$ & Ethylene glycol & SDS & 17.4 \\
\hline
\end{tabular}

Table. 4. Synthesis conditions and particle size of Ir-Ni BMNPs with Tri sodium citrate

\begin{tabular}{llclcc}
\hline $\begin{array}{l}\text { S. } \\
\text { No. }\end{array}$ & Precursor & $\begin{array}{c}\text { Ratio of } \\
\text { precursors } \\
\text { (\%) }\end{array}$ & Solvent & Surfactant & $\begin{array}{c}\text { Approx. particle size in } \\
\text { (nm) by XRD }\end{array}$ \\
\hline $\mathbf{1}$ & $\mathrm{IrCl}_{3} 3 \mathrm{H}_{2} \mathrm{O}$ and $\mathrm{NiCl}_{2} 6 \mathrm{H}_{2} \mathrm{O}$ & $100: 0.0$ & Ethylene glycol & TSC & 258.7 \\
$\mathbf{2}$ & $\mathrm{IrCl}_{3} 3 \mathrm{H}_{2} \mathrm{O}$ and $\mathrm{NiCl}_{2} 6 \mathrm{H}_{2} \mathrm{O}$ & $75: 25$ & Ethylene glycol & TSC & 32.5 \\
$\mathbf{3}$ & $\mathrm{IrCl}_{3} 3 \mathrm{H}_{2} \mathrm{O}$ and $\mathrm{NiCl}_{2} .6 \mathrm{H}_{2} \mathrm{O}$ & $50: 50$ & Ethylene glycol & TSC & 191.7 \\
$\mathbf{4}$ & $\mathrm{IrCl}_{3} 3 \mathrm{H}_{2} \mathrm{O}$ and $\mathrm{NiCl}_{2} .6 \mathrm{H}_{2} \mathrm{O}$ & $25: 75$ & Ethylene glycol & TSC & 31.3 \\
$\mathbf{5}$ & $\mathrm{NiCl}_{2} .6 \mathrm{H}_{2} \mathrm{O}$ and $\mathrm{IrCl}_{3} .3 \mathrm{H}_{2} \mathrm{O}$ & $100: 0.0$ & Ethylene glycol & TSC & 14.1 \\
\hline
\end{tabular}

\subsection{HR-TEM (High resolution transmission electron microscope)}

The high resolution study of the nanoparticles using HRTEM provided further insight into the morphology and size of Ir-Ni BMNPs. HRTEM images obtained are shown in the Fig. 4(A) and 4(B). The size range of Ir-Ni (3:1)/PVP and Ir-Ni (1:1)/ PVP-BMNPs varies between 1.0-4.2 nm and 1.0$3.5 \mathrm{~nm}$ as can be seen from the histogram in Image (i) and (ii) respectively. The approximate size of PVP stabilized Ir-Ni (3:1) and Ir-Ni (1:1) BMNPs is $2.36 \mathrm{~nm}$ and $1.77 \mathrm{~nm}$. Selected area electron diffraction (SAED) is a crystallographic experimental technique that can be performed inside a High resolution transmission electron microscope (HRTEM). Spotty circular rings in Image (1) and (2) are seen in the SAED pattern which further indicate the crystalline nature and reduced size of the particles. ${ }^{39,40}$ Fig. 4(a) demonstrates Ir shell on Ni core of particles while Fig. 4(b) shows crystallites arranged in different planes. 

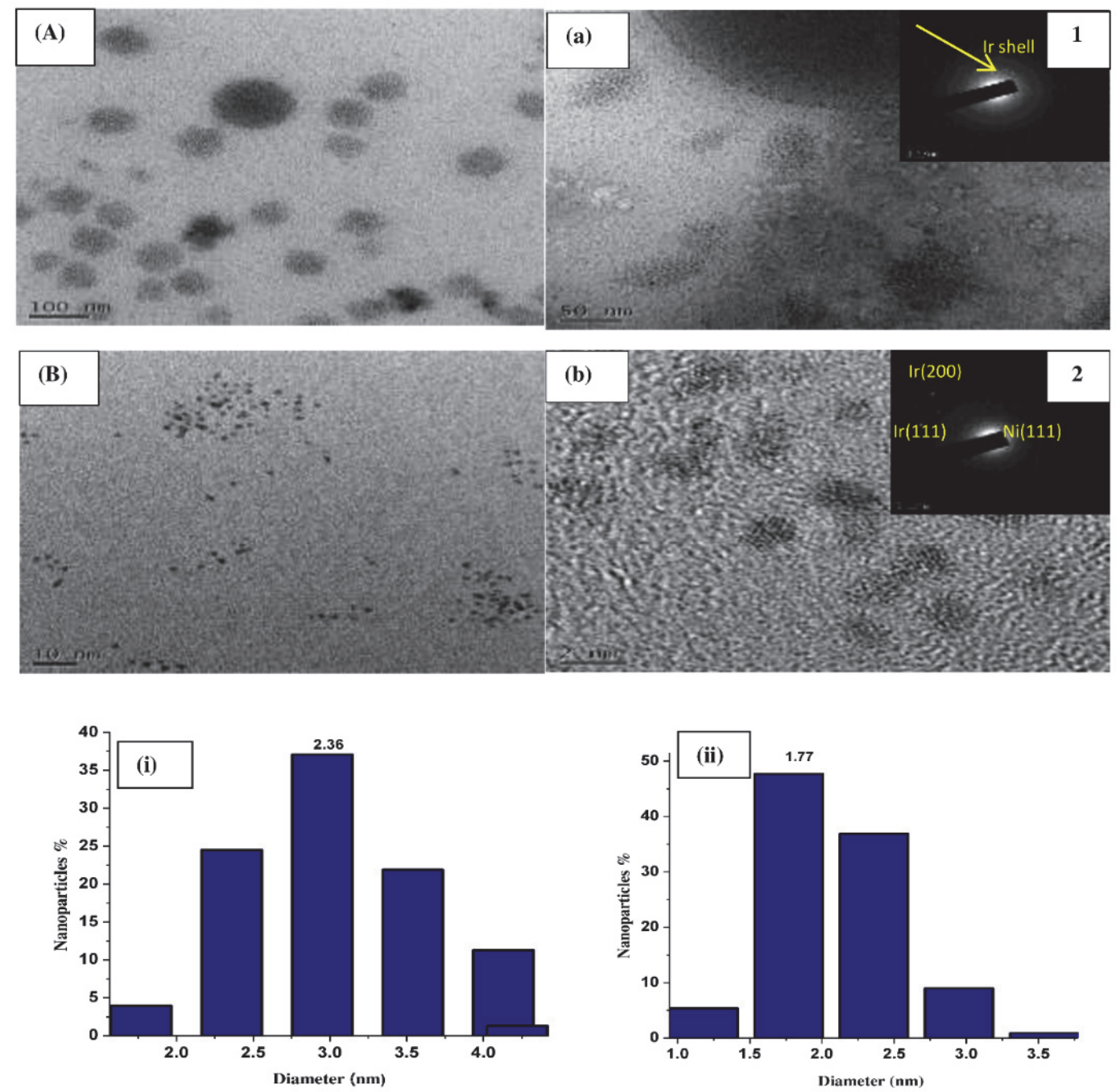

Fig. 4. HRTEM image of PVP stabilized (A) Ir-Ni (3:1) and(B) Ir-Ni (1:1) BMNPs

\subsection{FESEM and EDX analysis}

In order to analyse the surface structure of the bimetallic nanoparticles Field emission scanning electron microscopy (abbreviated as FESEM) was performed. FESEM images in (Fig. 5) show that IrNi (3:1)/PVP-BMNPs consist of polygonal shape aggregates (at high magnification having $6 \mathrm{um}$ ). From Fig. 5(A) it is clear that the Ir-Ni (3:1)/PVP-BMNPs nearly have undeviating size and well dispersed in bulk state by avoiding their accretion due to coordination with $\mathrm{Ir}$, Ni ions in the composite mixture. ${ }^{32}$ From Fig. 5(B) it is clear that Ir-Ni (1:1)/PVP-BMNPs are irregular in shape with some agglomeration. Energy dispersive X-ray analysis is a technique that is used to find out the elemental composition. The images of Ir-Ni (3:1)/PVP and Ir-Ni (1:1)/PVP-BMNPs are shown in Fig. 5(a) and 5(b) while the elemental data is shown in Table 5. The EDX spectrum in Fig. 5(a) and 5(b) confirms the presence of Ir, Ni, C, and $\mathrm{O}$ elements. In Fig. 5(b) the presence of $\mathrm{Ca}$, S elements may be due to some minor impurities. The elemental composition percentage ratio of $\operatorname{Ir}-\mathrm{Ni}(3: 1)$ and $\operatorname{Ir}-\mathrm{Ni}(1: 1)$ in Table 5 are 92:8 and 98:1 respectively. Thus, atomic composition study by EDX analysis indicates that the resultant particles are in core shell structure with $\mathrm{Ni}$ core and Ir shell. ${ }^{41}$ 

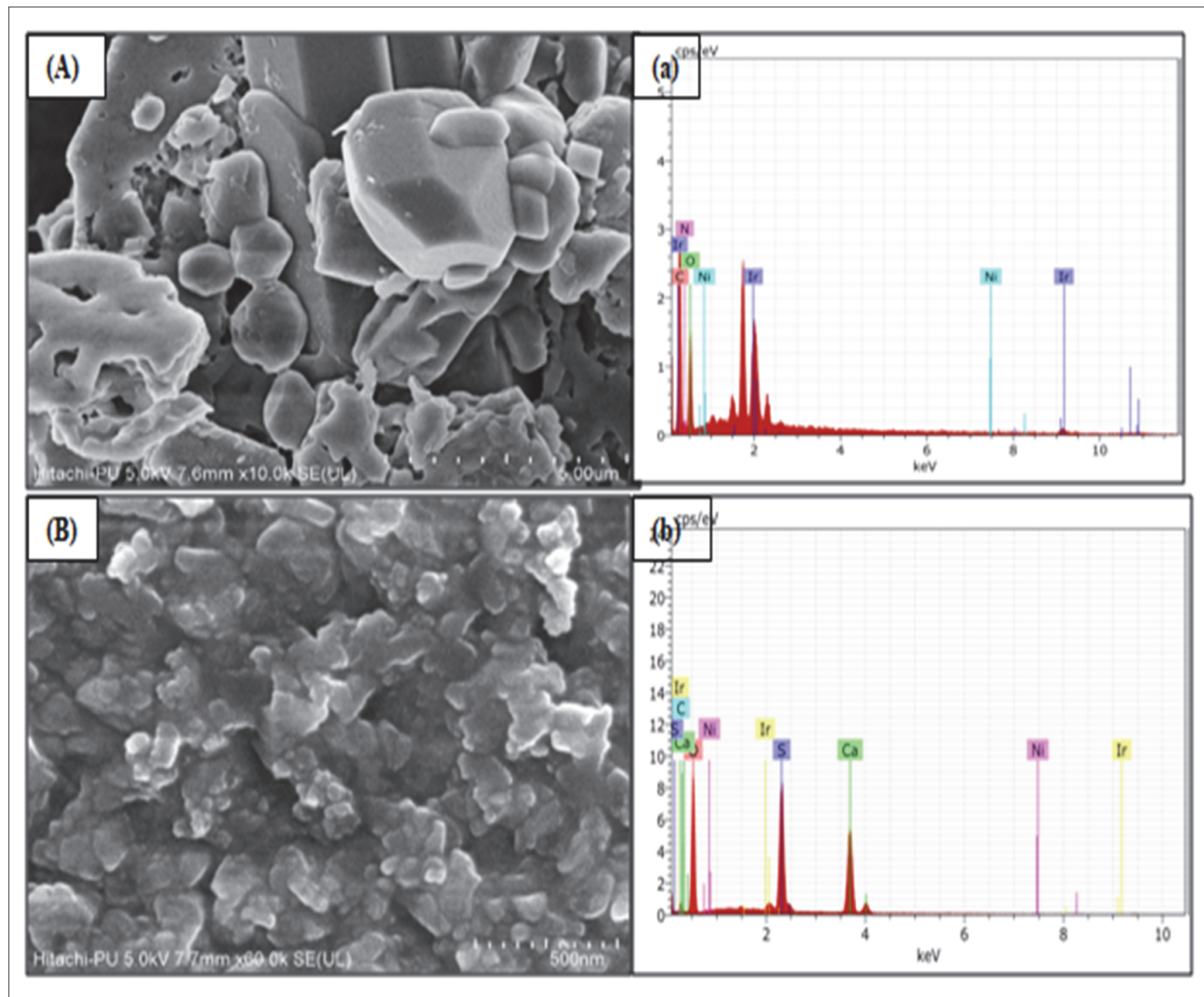

Fig. 5. FESEM images of PVP stabilized (A) Ir-Ni (3:1) BMNPs and (B) Ir-Ni (1:1) BMNPs and EDX images of PVP stabilized (a) Ir-Ni (3:1) and (b) Ir-Ni (1:1) BMNPs

Table 5. EDX analysis of PVP stabilized (A) Ir-Ni (3:1) and (B) Ir-Ni (1:1) ratio BMNPs

\begin{tabular}{ccccc}
\hline Element & $\begin{array}{c}\text { Weight \% } \\
\text { (A) }\end{array}$ & $\begin{array}{c}\text { Atomic \% } \\
\text { (A) }\end{array}$ & $\begin{array}{c}\text { Weight \% } \\
\text { (B) }\end{array}$ & $\begin{array}{c}\text { Atomic \% } \\
\text { (B) }\end{array}$ \\
\hline $\mathbf{C}$ & 42.75 & 56.82 & 5.10 & 8.50 \\
$\mathbf{O}$ & 31.58 & 31.50 & 56.69 & 71.01 \\
$\mathbf{I r}$ & 16.45 & 1.37 & 1.19 & 0.12 \\
$\mathbf{N i}$ & 0.23 & 0.06 & 0.11 & 0.04 \\
\hline
\end{tabular}

\subsection{Role of surface active agents}

Surface active agents are wetting agents that lower the surface tension of a liquid and control the fusion of nanocrystals. ${ }^{42,43}$ To explore the effect of surface active agents on particle size of nanocrystals synthesized by modified polyol process three types of surface active agents PVP (non-ionic), CTAB (cationic), and SDS, TSC (anionic) were used. PVP is considered an excellent stabilizer as it represents favourable protecting qualities owing to its particular structure. It is a homopolymer having a polyvinyl backbone and its repeating units contain highly polar $-\mathrm{CONH}_{2}$ groups that negotiate hydrophilic and polar attracting qualities, and also having a non polar methylene group both in the backbone and in the ring that negotiate hydrophobic qualities. The $\mathrm{N}$ and $\mathrm{O}$ in the polar groups have a strong affinity for metal ions and metal nanocrystals. ${ }^{44}$ Calculated particle size of Ir-Ni/surfactants (PVP, CTAB, SDS, and TSC) stabilized BMNPs by XRD is shown in Tables 1-4. Ultimate result was found with PVP as size regulator in comparison with CTAB, SDS, and TSC. Size of Ir-Ni (1:1)/PVP BMNPs is $0.8 \mathrm{~nm}$ and 
of CTAB, SDS, and TSC is $10.3 \mathrm{~nm}, 246.2 \mathrm{~nm}$, and $191.7 \mathrm{~nm}$ respectively. There is also a comparison between anionic surfactants SDS and TSC. Although both are anionic surfactants, they can be seen in Table 3 and 4. TSC stabilized nanoparticles have smaller particle size in comparison of SDS stabilized nanoparticles. Trisodium citrate works as microreactor for presenting the reaction and a steric surface active agent to inhibit the agglomeration. ${ }^{23}$

\section{Conclusions}

In this study Ir, Ni MNPs and Ir-Ni BMNPs in different ratios $(3: 1,1: 3$, and 1:1) have been successfully synthesized by modified polyol reduction method using different surface active agents such as PVP, CTAB, SDS, and TSC. The addition of surface active agents can affect particle size, coagulation, and flocculation. Therefore, surface active agents play an imperative role in the synthesis of nanoparticles. The synthesized nanoparticles remain more stable and smaller in size with non-ionic surface active agent PVP as compared to CTAB, SDS, and TSC even after several months. X-ray diffraction studies verify that the BMNPs are FCC and amorphous in nature. FTIR corresponds to the interaction between surface active agents and nanoparticles. HRTEM studies reveal that Ir-Ni (3:1)/ PVP and Ir-Ni (1:1)/PVP-BMNPs are small in size and less dispersed. Particle size range of these nanoparticles is from (1.77-2.36)nm. FESEM images show that nanoparticles are in quasi spherical shape. Atomic composition studies by EDX analysis indicate that the resultant particles are core shell structure with Ni core and Ir shell. Thus PVP supported Ir-Ni (1:1) BMNPs are small in size $1.77 \mathrm{~nm}$ less dispersed and amorphous in nature. Therefore, as-synthesized Ir-Ni/ Surfactant supported BMNPs may provide a stable platform for the development of heterogeneous catalysis, green chemistry, and environmentally benign protocol in the near future.

\section{Acknowledgements}

The authors are grateful to Gurukul Kangri University, Haridwar for providing the basic facilities for this research work. The authors are also thankful to IIT, Roorkee for XRD analysis, IIT, Bombay for HRTEM analysis and Panjab University Chandigarh for FESEM and FTIR analysis.

\section{Experimental}

\subsection{Materials}

All chemicals were achieved from usual profitable sources and used without further analysis. Iridium trichloride trihydrate $\left(\mathrm{IrCl}_{3} .3 \mathrm{H}_{2} \mathrm{O}\right)$, nickel chloride hexahydrate $\left(\mathrm{NiCl}_{2} .6 \mathrm{H}_{2} \mathrm{O}\right)$ (used as precursor salt) and ethane-1,2-diol $\left(\mathrm{C}_{2} \mathrm{H}_{6} \mathrm{O}_{2}\right)$ (used as solvent and reductant) were purchased from SRL. Sodium hydroxide $(\mathrm{NaOH})$ pellets were obtained from Merck. PVP, CTAB, SDS, and TSC, (used as capping agents) were purchased from SRL. Double distilled water was used to prepare all solution.

\subsection{Equipments}

UV-Vis spectra were recorded using systronic Double-beam spectrophotometer -2203 in the range of 220-800. The samples were in the liquid state and quartz cuvettes having an optical path length of $1.00 \mathrm{~cm}$. The Fourier transform infrared (FT-IR) spectra were measured with FTIR (Perkin Elemer) in the range of $4000-400 \mathrm{~cm}^{-1}$ using the $\mathrm{KBr}$ Pellet technique. The X-ray diffraction (XRD) measurements were performed by using on the dry powders using Bruker Axis D-8 Advance diffractometer with $\mathrm{CuK}_{\alpha}$ $(\lambda=0.154 \mathrm{~nm})$ radiation over a range of $2 \theta$ angles from $20-90^{\circ}$. High resolution transmission electron microscope (HRTEM) were performed using (HRTEM 200kv JEM 2100F), operate at an accelerating voltage of 20-200kv. Samples for HRTEM analysis were obtained by using dilute solution of nanocrystals. Field emission electron microscope (JSM 6100 JEOL) SEM was used for surface morphology and shape of nanocrystals. 


\subsection{Synthesis of monometallic and bimetallic nanocrystals}

In the present work, synthesis of Ir, Ni monometallic and Ir-Ni bimetallic nanocrystals in peculiar ratios $(3: 1,1: 3$, and 1:1) using precursor salts of iridium trichloride and nickel chloride by modified polyol reduction method was carried out. To monitor the progression of the nanocrystals formation UV-Visible double beam spectrophotometer is used. A constant peak in the spectrum is the gesture of formation of stable monometallic and bimetallic nanacrystals. Polymer stabilized bimetallic nanocrystals in alcohol were prepared by concurrent reduction of the two corresponding metal salts. Precursor salts of iridium trichloride $(0.0059 \mathrm{~g})$ and nickel chloride $(0.0059 \mathrm{~g})$ in disparate ratios were dissolved in $25 \mathrm{ml}$ ethylene glycol. A certain amount of one of the surfactant (PVP, CTAB, SDS, and TSC) was added to this solution and the system was stirred at magnetic stirrer until total dissociation of surfactant occurs. To maintain $\mathrm{p}^{\mathrm{H}}$ sufficient amount of $\mathrm{NaOH}$ is added. After being stirred at room temperature the total content was delivered into tri-neck flask and reflux for $3 \mathrm{hrs}$ in oil bath at $140^{\circ} \mathrm{C}$ $180^{\circ} \mathrm{C}$ temperature. After refluxing the color of the solution changes from pale yellow to blackish brown.

\section{References}

1 Sharma G., Kumar A., Sharma S., Naushad M., Dwivedi R. P., ALOthman Z. A., and Mola G. T. (2019) Novel development of nanoparticles to bimetallic nanoparticles and their composites: a review. J. King Saud Univ. Sci., 31 (2) 257-269.

2 Tejamaya M., Römer I., Merrifield R. C., and Lead J. R. (2012) Stability of citrate, PVP, and PEG coated silver nanoparticles in ecotoxicology media. Environ. Sci. Technol., 46 (13) 7011-7017.

3 Li Y., Boone E., and El-Sayed M. A. (2002) Size effects of PVP-Pd nanoparticles on the catalytic suzuki reactions in aqueous solution. Langmuir., 18 (12) 4921-4925.

4 Singh S. B. (2016) Iridium chemistry and its catalytic applications: a brief review. Green Chem. Technol. Lett., 2 (4) 206-210.

5 Liu Z., andSadler P. J. (2014) Organoiridium complexes: anticancer agents and catalysts. Acc. Chem. Res., 47 (4) 1174-1185.

6 Stowell C. A., and Korgel B. A. (2005) Iridium nanocrystals synthesis and surface coating-dependent catalytic activity. Nano Lett., 5 (7) 1203-1207.

7 Islam F., Hossain M. A., Shah N. M., Barua H. T., Kabir M. A., Khan M. J., and Mullick R. (2015) Synthesis, characterization, and antimicrobial activity studies of Ni(II) complex with pyridine as a ligand. J. Chem., 2015.

8 Xue H. A. N., Wei C. H. U., Ping N. I., Shi-zhong LUO, and Tao Z..(2007) Promoting effects of iridium on nickel based catalyst in ammonia decomposition. J. Fuel Chem. Technol., 35 (6) 691695.

9 Kalwar N. H., Sirajuddin., Soomro R. A., Sherazi S. T. H., Hallam K. R., and Khaskheli A. R. (2014) Synthesis and characterization of highly efficient nickel nanocatalysts and their use in degradation of organic dyes. Int. J. Met., 2014.

10 Egeberg A., Dietrich C., Kind C., Popescu R., .,Gerthsen D., Behrens S., and Feldmann C. (2017) Bimetallic NiIr 4 and NiOs4 alloy nanoparticles and their catalytic performance in hydrogenation reactions. Chem. Cat. Chem., 9 (18) 3534-3543.

11 Garcia-Gutierrez D. I., Gutierrez-Wing C. E., Giovanetti L., Ramallo-Lopez J. M., Requejo F. G., and Jose-Yacaman M. (2005) Temperature effect on the synthesis of Au-Pt bimetallic nanoparticles. J. Phys. Chem. B., 109 (9) 3813-3821.

12 An K., and Somorjai G. A. (2015) Nanocatalyst I: synthesis of metal and bimetallic nanoparticles and porous oxides and their catalytic reaction studies. Catal. Lett., 145 (1) 233-248.

13 Kim T., Kabayashi K., and Nagai M. (2007) Preparation and characterization of platinum-ruthenium bimetallic nanoparticles using reverse microemulsions for fuel cell catalyst. J. Oleo Sci., 56 (10) 553-562. 
14 Singh H. P., Gupta N., Sharma S. K., and Sharma R. K. (2013) Synthesis of bimetallic Pt-Cu nanoparticles and their application in the reduction of rhodamine B. Colloids Surf. A: Physicochem. Eng. Asp., 416 43-50.

15 Duan M., Jiang L., Zeng G., Wang D., Tang W., Liang J., Wang H., He D., Liu Z., and Tang L. (2020) Bimetallic nanoparticles/metal-organic frameworks: synthesis, applications and challenges. Appl. Mater. Today., 19100564.

16 Ashraf M. A., Peng W., Zare Y., and Rhee K. Y. (2018) Effects of size and aggregation/ agglomeration of nanoparticles on the interfacial/interphase properties and tensile strength of polymer nanocomposites. Nanoscale Res. Lett., 13 (1) 214.

17 Wang W., Gu B., and Liang L. (2004) Effect of surfactants on the formation, morphology, and surface property of synthesized $\mathrm{SiO}_{2}$ nanoparticles. J.Disper. Sci. Technol., 25 (5) 593-601.

18 Al-Thabaiti S.A., Malik M. A., Al-Youbi A. A., Khan Z., and Hussain J. I. (2013) Effects of surfactant and polymer on the morphology of advanced nanomaterials in aqueous solution. Int. J. Electrochem. Sci., 8 (1) 204-218.

19 Morsy S. M. (2014) Role of surfactants in nanotechnology and their applications. Int. J. Curr. Microbiol. App. Sci., 3 (5) 237-260.

20 Simoes M., Pereira M. O., and Vieira M. J. (2005) Action of a cationic surfactant on the activity and removal of bacterial biofilms formed under different flow regimes. Water Res., 39 (2-3) 478-486.

21 Tiwari S., Mall C., and Solanki P. P. (2018) Surfactant and its applications: a review. Int. J. Eng. Res. Appl., 8 (9) 61-66.

22 Arslan A., Topkaya E., Bingol D., and Veli S. (2018) Removal of anionic surfactant sodium dodecyl sulfate from aqueous solutions by $\mathrm{O}_{3} / \mathrm{UV} / \mathrm{H}_{2} \mathrm{O}_{2}$ advanced oxidation process: process optimization with response surface methodology approach. Sustain. Environ. Res., 28 (2) 65-71.

23 Thottoli A. K., and Unni A. K. A. (2013) Effect of trisodium citrate concentration on the particle growth of $\mathrm{ZnS}$ nanoparticles. J. nanostruct. Chem., 3 (1) 56.

24 Al-Harbi L. M., Kosa S. A., Baloch M. K., Bhatti Q. A., and El-Mossalamy E. S. E. B. H. (2016) Adsorption of polyvinylpyrrolidone over the silica surface: as affected by pretreatment of adsorbent and molar mass of polymer adsorbate. Int. J. Polym. Sci., 2016.

25 Shukla M., and Sinha I. (2018) Catalytic Aactivation of PVP-stabilized gold/silver cluster on pnitrophenol reduction: a DFT. Density Functional Calculations-Recent Progresses of Theory and Application, 153.

26 Yue H., Zhao Y., Ma X., and Gong J. (2012) Ethylene glycol: properties, synthesis, and applications. Chem. Soc. Rev., 41 (11) 4218-4244.

27 Dong Y. Y., Liu S., Meng L. Y., Wang B., Bian J., and Ma M. G. (2016) An efficient ultrasonicassisted synthesis of Ag@Agcl@cellulose composites in ethylene glycol solvent. Mater. Lett., 165 210-213.

28 Goel A., and Bhatt R. (2012) Synthesis and characterization of nanoscale colloidal iridium metal clusters by chemical reduction method using monohydric and dihydric alcohols. Int. J. Chem. Appl.,4 (2) 111-121.

29 Sujata J., Asokan S., and Kumar S. R. (2017) Antioxidant effect and phytochemical analysis of chloroform extract of cassis fistula using FT-IR, HPLC and GC-MS analysis. Int. J. Pharm. Sci. Rev. Res., 46 (1) 129-133.

30 Goel A., and Lasyal R. (2018) Facile synthesis of $\mathrm{IrO}_{2}$ nanoclusters and their application as catalysts in the degradation of azo dyes. Turk. J. Chem., $42941-957$.

31 Goel A., and Sharma S.(2012) Colloidal iridium nanoparticles in the oxidation of hexacyanoferrate(III) in alkaline medium - a kinetic study. J. Indian Chem. Soc., 89 (4) 507-512.

32 Goel A., and Chaudhary M. (2018) Highly dispersed PVP-supported Ir-Ni bimetallic nanoparticles as high performance catalyst for degradation of metanil yellow. Bull. Mater. Sci., 41 (3) 81.

33 Roy K., Sarkar C. K., and Ghosh C. K. (2015) Photocatalytic activity of biogenic silver nanoparticles synthesized using yeast (saccharomyces cerevisiae) extract. Appl. Nanosci., 5 953-959.

34 Saffari J., Mir N., Ghanbari D., Khandan-Barani K., Hassanabadi A., and Hosseini-Tabatabaei M. R. (2015) Sonochemical synthesis of $\mathrm{Fe}_{3} \mathrm{O}_{4} / \mathrm{ZnO}$ magnetic nanocomposites and their application in 
photocatalytic degradation of various organic dyes. J.Mater. Sci: Mater. Electron., 26 (12) 95919599.

35 Mahmoud S. A., Al-Shomar S. M., and Akl A. A. (2010) Electrical characteristics and nanocrystalline formation of sprayed iridium oxide thin films. Adv. Condens. Matter Phys., 2010.

36 Kundu S., and Liang H. (2011) Shape-selective formation and characterization of catalytically active iridium nanoparticle. J.Colloid Interface Sci.,354 (2) 597-606.

37 Darabdhara G., Das M. R., Amin M. A., Mersal G. A. M., Mostafa N. Y., Abd El-Rehim S. S., Szunerits S., and Boukherroub R. (2018) Au-Ni Alloy nanoparticles supported on reduced grapheme oxide as highly efficient electrocatalysts for hydrogen evolution and oxygen reduction reactions. Int. J. Hydrog. Energy., 43 (3) 1424-1438.

38 Chiang I. C., Chen Y. T., and Chen D. H. (2009) Synthesis of NiAu colloidal nanocrystals with kinetically tunable properties. J. Alloys Compd.,468 (1-2) 237-245.

39 Antoinette M. M., and Israel S. (2017) Synthesis and characterization of $\mathrm{Sm}_{2} \mathrm{O}_{3}$ nanoparticles using combustion method. Int. Res. J. Eng. Tech.,4 276-9.

40 Redon R., Ramirez-Crescencio F., and Fernandez-Osorio A. L. (2011) Solventless synthesis of iridium(0) nanoparticles. J.Nanopart. Res., 13 (11) 5959-5965.

41 Larios E., Molina Z., Maldonado A., and Tanori J. (2012) Synthesis and characterization of bimetallic copper gold nanoparticles. J. Disper.Sci.Technol.,33 (5) 719-723.

42 Mishra M., Muthuprasanna P., Prabha K. S., Rani P. S., Satish I. A., Chandiran I. S., Arunachalam G., and Shalini S. (2009) Basics and potential applications of surfactants-areview. Int. J. Pharmtech. Res., 1 (4) 1354-1365.

43 Heinz H., Pramanik C., Heinz O., Ding Y., Mishra R. K., Marchon D., Flatt R. J., Estrela-Lopis I., LIop J., Moya S., and Ziolo R. F. (2017) Nanoparticle decoration with surfactants: molecular interactions assembly and applications. Surf. Sci. Rep., 72 (1) 1-58.

44 Malina D., Sobczak-Kupiec A., Wzorek Z., and Kowalski Z. (2012) Silver nanoparticles synthesis with different concentration of polyvinylpyrrolidone. Dig. J. Nanomater.Bios., 7 (4) 1527-1534.

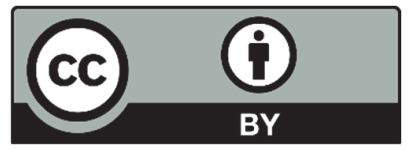

(C) 2021 by the authors; licensee Growing Science, Canada. This is an open access article distributed under the terms and conditions of the Creative Commons Attribution (CC-BY) license (http://creativecommons.org/licenses/by/4.0/). 